\title{
GNSS CORS NETWORK OF THE UNIVERSITY OF PALERMO: DESIGN AND FIRST ANALYSIS OF DATA
}

\author{
Gino DARDANELLI ${ }^{\text {(iD), Mauro LO BRUTTO }}{ }^{1}$ (D), Claudia PIPITONE $^{1 \text { (i) }}$
}

DOI: $10.21163 / G T \_2020.151 .05$

\begin{abstract}
:
Nowadays, technical and scientific researches are focused on the use of Global Navigation Satellite System (GNSS) Continuously Operating Reference Stations (CORS) networks due to their global impact on the satellite positioning. This study aims to describe the main steps developed by the University of Palermo for the realization of the GNSS CORS network distributed in the western part of Sicily (Italy). Specifically, it focuses on data availability, preliminary studies and analyses involving the GNSS CORS network, the geodetic framework used, the coordinates and displacements time series retrieved over time and the statistical analysis with the Cumulative Distribution Function (CDF). The analyses allowed to verify the network operating service and the quality of the recorded data during the first period of testing procedure $(2008-2012)$.
\end{abstract}

Key-words: GNSS; CORS; data analysis; time series

\section{INTRODUCTION}

In the last few decades, many investigations have been developed for the analysis of the three-dimensional (3D) positioning by using the Global Navigation Satellite System (GNSS) Continuously Operating Reference Stations (CORS). The scientific and technical applications developed in different parts of the continents (Snay and Soler, 2008) involved the CORS networks to evaluate the 3D positioning in real-time (Network Real-Time Kinematic, NRTK) and in post-processing analyses. Indeed, the innovative framework of the GNSS CORS networks allowed receiving the most reliable differential corrections over an area by using the Virtual Reference Station (VRS, Wanninger, 2003), the FlächenKorrektur-Parameter (FKP, Kim et al., 2017) or the Multi Reference Station (MRS, Fotopoulos and Cannon, 2001) approaches. As a consequence, the use of CORS networks allowed increasing the distances between the reference stations, reducing contemporary the total amount of CORS distributed over the same area. Also, many advantages have been observed in terms of economic impact and network management (Grejner-Brzezinska et al., 2005a).

The scientific implementations using the CORS networks were also focused on the analysis and correction of the ionospheric and tropospheric errors (Grejner-Brzezinska et al., 2005a; Zhang and Lachapelle, 2001); the latter, in particular, through the Zenith Tropospheric Delay (ZTD) estimation. Many analyses have been developed to evaluate the use of a global reference system and its inconstancy (Bruyninx et al., 2012; Kenyeres and Bruyninx, 2004) and worldwide the geodynamic studies, over seismic areas (Altiner et al., 2013). Other technical implementations have been also developed in different fields, such as agriculture (Osório and Cunha . 2013), mining (Jing-xiang and Hong, 2009), structures monitoring, utilities, surveying and land cadastral management (Rizos and Satirapod, 2011;

\footnotetext{
${ }^{1}$ Department of Engineering, University of Palermo, Viale delle Scienze, 90128 Palermo, Italy (e-mail: gino.dardanelli@unipa.it; mauro.lobrutto@unipa.it; claudia.pipitone02@unipa.it)
} 
Erenoglu 2017; Abidin et al., 2015), Mobile Mapping Systems (MMS, Gordini et al., 2007), Geographical Information System (GIS, Huang et al., 2011) or mapping and airborne Unmanned Aerial Vehicle (UAV, Forlani et al., 2018; Ebolese et al., 2019), road and rail transport and logistics (Marais, 2017), maritime navigation (Angrisano et al., 2013), and aviation (Zhang and Zhan, 2016). Recently, the emerging GNSS framework proposed by the Beidou and Galileo Constellations will further augment CORS demand through use with dual-frequency mobile phones (Dabove and Di Pietra, 2019; Radicioni and Stoppini, 2019; Robustelli et al., 2019).

Nowadays, worldwide, the GNSS CORS networks are widely distributed and they are classified as global, regional, national and local networks based on the covered region (Soler, 2011).

In Italy, several distributed CORS networks are managed by public or private institutions, known as national CORS networks and local level based networks, respectively. In 1994, the first national CORS network, called Geodetic Data Archiving Facility (GeoDAF), has been installed by the Agenzia Spaziale Italiana (ASI). The network (Vespe et al., 2000) is managed by ASI's Space Geodesy Center "Giuseppe Colombo" (ASI/CGS), belonging to the International Laser Ranging Service (ILRS), of International VLBI Service (IVS) and International GNSS Service (IGS). All stations belonging to the GeoDAF are able to provide daily and hourly recorded data in Receiver INdependent Exchange (RINEX) format; most of them are also able to supply data in real-time within the EUREF IP project. Since 1996, all data, available from GeoDAF and other CORS networks distributed in Italy, are able to support all users through an EUREF Local Analysis Center (GeoDAF, 2020). Since 2004, in Italy, the Istituto Nazionale di Geofisica e Vulcanologia (INGV) has managed a national CORS network, made up of $\approx 200$ CORS (Avallone et al., 2010), called Rete Integrata Nazionale GPS (RING) mainly devoted to tectonic studies; this network provides the availability of RINEX data at 30 second online.

In 2009, the Istituto Geografico Militare Italiano (IGMI, the Official Italian geodetic entity) has developed the national CORS network, called Rete Dinamica Nazionale (RDN), made up of 99 CORS; 21 of those were included in the EUREF Permanent Network (EPN), and other 14 stations were used for the computation of the International Terrestrial Reference Frame 2005 (ITRF2005) solution (Baroni et al., 2009). The ITRF2005 coordinates of these stations are also converted to the ETRF2000 frame by using the Helmert parameters (Boucher and Altamimi, 2011). Indeed, the RDN also provides the European Terrestrial Reference Frame (ETRF2000, epoch 2008.0), updating the previous reference system ETRS89 of the static GPS geodetic network, called IGM95; these reference stations belong to different Research Centres, Universities and Public Institutions. Consequently, in 2013, the IGMI has monitored the GNSS network, re-computing periodically the stations' positions and analysing the time series of the stations over the first five years of their activity. It was found that $\approx 20 \%$ of the 99 RDN stations were not able to transmit data correctly and many of those have been dismissed (Maseroli, 2015). This breakdown caused the inactivity of several distributed areas. Thus, a new version of the RDN network, called RDN2, restoring the correct geometry between the stations, has been materialised by the IGMI replacing the old CORS and re-computing their updated positions (epoch 2014.4). In Italy, other two private national CORS networks are also available. Specifically, 133 of these CORS are managed by Hexagon Geosystems, Italian Positioning Service (ItalPoS) (HxGN SmartNet 2020) and more than 200 CORS are managed by Topcon Italia, (NetGeo 2020). These private national CORS, referred to the ETRF2000RDN reference frame, were developed to make available real-time corrections in the $3 \mathrm{D}$ 
positioning with VRS, FKP, MRS approaches and RINEX data for post-processing analyses and technical research.

Many other local level based networks, managed by Universities, public and private institutions are also available in Italy, improving the NRTK positioning for technical research, increasing the number of available CORS in the whole country. Data from these stations are also used for scientific and experimental research (Fig. 1).

Since 2014, the University of Padua has recomputed the weekly position of GeoDAF, RING, RDN, ItalPos, Netgeo and other local networks, based on the combination of seven daily solutions with Bernese 5.2 software. All these CORS belong to the so-called Italian GNSS Network, made up of $\approx 700$ GNSS CORS, available in Italy and the neighbouring countries. The time series and the horizontal and vertical velocity fields of these stations are made available on a specific website (Italian GNSS Network 2020).

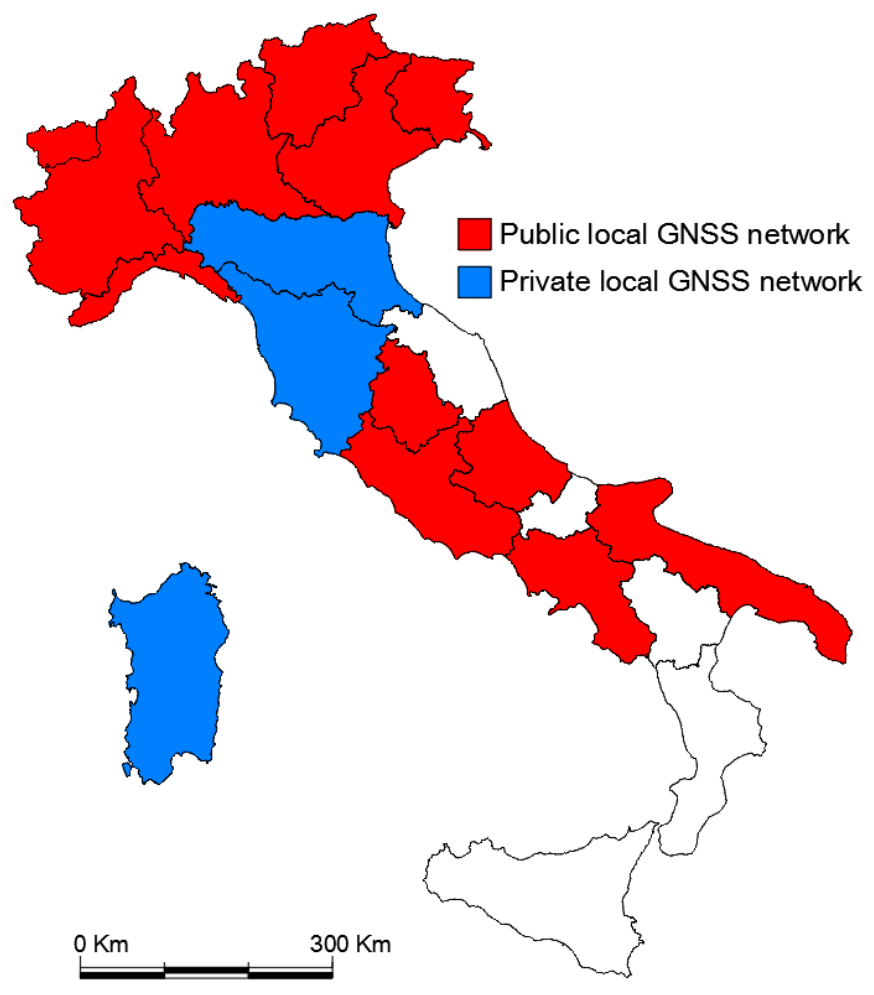

Fig. 1. Map of the local level based network in Italy.

Up to 2008, in Sicily there was not a local GNSS network; thus the University of Palermo has designed and realised the first local level based network in the central-western part of the island. The management of the GNSS CORS network, made up of 8 stations, used for technical and scientific purposes, was preliminary entrusted to the University (until 2013); later, the stations were included in the Netgeo GNSS network, managed by Topcon Italy, due to the scientific collaboration between the latter and the University of Palermo, aimed to realize the first local level based network in Sicily. 
The CORS network set up in the western part of Sicily has been tested and data was used for several scientific works focused on: dams monitoring (Pipitone et al., 2018; Dardanelli and Pipitone, 2017; Dardanelli et al., 2014), geological analyses (Stocchi et al., 2017), trajectories calculation of MMS (Dardanelli et al., 2015; Dardanelli and Carella, 2013), integrated survey in archaeological context (Fazio et al., 2019; Ebolese et al., 2019) and also geodynamic research (Barreca et al., 2020).

The aim of this study is the description of the developments of a new infrastructure able to support scientific and technical research by Universities, private users and National Agencies for the site monitoring and control, realized by the University of Palermo. Specifically, the study points out the main activities related to the data availability and its preliminary use for scientific purposes, the geodetic frame, the time series and the statistical analyses; the latter developed through the implementation of a Cumulative Distribution Function (CDF).

This study focuses on the analysis of the GNSS CORS network over the first period of operability of approximately 5 years (from 2008 to 2012); the choice of this preliminary dataset is based on different motivations. Firstly, for each GNSS CORS, it is important to verify the quality of the data obtained throughout the analysis of the GNSS observations during the first period. This approach allows the validation of the infrastructure for technical and scientific applications according to the network's installation purposes. Moreover, the analysis of the correctness of this preliminary dataset was important because since 2013 the data retrieved from UNIPA GNSS CORS network has been used for the computation of the RDN2 network (EPN subnetwork), managed by the most important Italian cartographic institute (IGMI). In addition, from this period (2013), data has been made available for the evaluation of the national reference framework by the IGMI and for technical researches able to investigate the horizontal and vertical velocity map (Maseroli, 2015). Specifically, the EPN recommends the use of the first five years of data for the inclusion of a CORS within a network (Bruyninx, 2019).

The use of RINEX files since the first years of data acquisition is common in the scientific field, as demonstrated by several studies, e.g. the analysis conducted in 2009 for homogeneous reprocessing of the EUREF permanent network based on the 1996-2003 dataset (Kenyeres et al., 2009) or the analysis of the performances and the time series of CORS local network (Baniulis, 2017). Specifically, in the latter, the authors analysed in a succeeding period (2017) the data collected during a previous one, between 2008 and 2011.

The paper is organized as follows: the description of the CORS network (preliminary analyses, network project design and its materialization, description of the instrumentation) is discussed in Section 2. The software used for the preliminary analyses, the computation of the GNSS time series and the geodetic frame are described in Section 3; the results of the analyses are presented in Section 4. Finally, the conclusions and future applications are reported in Section 5.

\section{GNSS CORS NETWORK DEVELOPED BY UNIVERSITY OF PALERMO}

\subsection{Preliminary studies and network project design}

Preliminary studies for the materialization of the GNSS network have deeply analysed the importance of fixing a minimum number of CORS and the distance between them, assuming that no specifications are available in literature. Only few recommendations are available from experimental tests developed for NRTK applications. Some of those have considered the maximum distance to be used between the reference stations of 
approximately $200 \mathrm{~km}$ (Grejner-Brzezinska et al., 2005b); but generally, the distances to be used between the stations are within the range $50-80 \mathrm{~km}$, to avoid exceeding the maximum value $(\approx 200 \mathrm{~km})$ (Benciolini et al., 2006).

The geometric configuration of the GNSS CORS network proposed by the University of Palermo (UNIPA) considered the shape of the area to be monitored; specifically, the distribution of the CORS was conceived along the boundary of the western part of the island. Just to avoid exceeding more than $100 \mathrm{~km}$ between the CORS, another reference station has been installed in the hinterland, approximately barycentric between the CORS.

Other two existing CORS have been included in the network project design, one installed on the top of a building at the University of Palermo (PALE), the other in Termini Imerese (TERM). Other three CORS have been installed in the main cities of the western part of Sicily. Specifically, they are located in Trapani (TRAP), Agrigento (AGRI) and Caltanissetta (CALT); while the remaining were installed in little cities or towns: Partinico (PART), Campobello di Mazara (CAMP) and Prizzi (PRIZ). Totally, 8 CORS belong to the UNIPA GNSS network; the distances between the reference stations, influenced by the position of the buildings allocating the GNSS instrumentations, are included within the range 22 - $83 \mathrm{~km}$ (Fig. 2).

Almost all UNIPA CORS (TRAP, TERM, PART, CAMP, PRIZ) have been installed at Institutions interested in the collaboration with the University for scientific research, mainly secondary schools. The schools made available suitable areas where the instrumentation and the internet connection have been only used for the project. Only PALE and AGRI CORS have been installed at the Universities, while CALT CORS has been installed at the Genio Civile office.

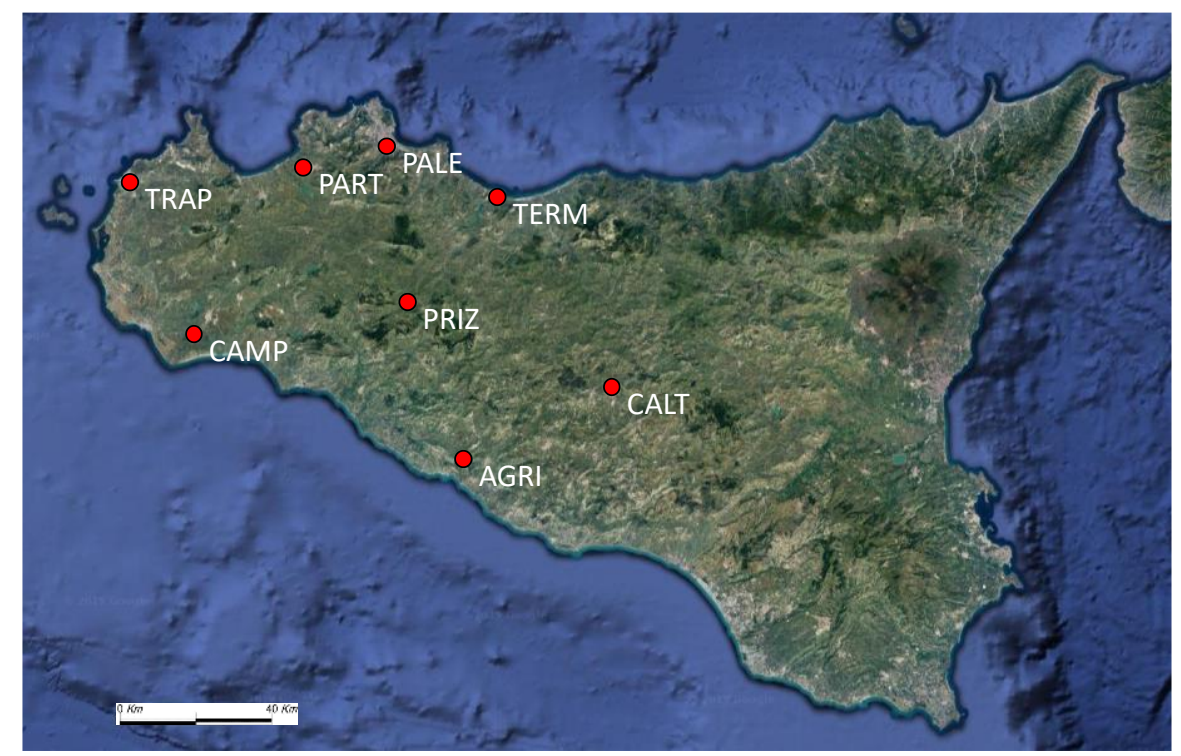

Fig. 2. Location of the UNIPA GNSS CORS (from Google Maps@)).

\subsection{Materialization and installation of the CORS}

The materialization of the GNSS CORS was relatively easy to be installed. This steps could be realised using different solutions; indeed many GNSS Institutions, for example, 
the International GNSS Service (IGS), the University NAVSTAR Consortium (UNAVCO) and the National Geodetic Survey (NGS, Anderson et al., 2000) have made standard procedures for this purpose.

Depending on the use of the GNSS CORS, the instrumentations can be fixed directly on the ground, (e.g. for geodynamic analyses), or on the top of the buildings (e.g. for technical purposes), but generally, the instrumentation is fixed with concrete or steel pillars, three-dimensional structures or also invar and steel beams (Anderson et al., 2000).

To determine the correct position of the GNSS instrumentation, some requirements needed to be satisfied, such as preventing the presence of obstacles that could restrict the satellites' visibility with cut-off angles more than five degrees, or preventing the presence of mirroring surfaces that could cause the multipath effect, or moreover preventing the presence of TV or mobile repeaters that could cause electromagnetic disturbances on the GNSS signal. Indeed, as discussed in previous works (Edwards et al., 2010), some investigations have been developed to preliminary investigate and analyse the quality of the signal with acquisitions of few hours.

Specifically, the UNIPA GNSS CORS have been installed on steel pillars placed on the top of selected buildings. Some of them have been fixed on reinforced concrete bases (PALE, TRAP, PRIZ), the others have been fixed with steel clamps and flanges (Fig. 3). Both materializations allowed obtaining strong and resistant structures over time.

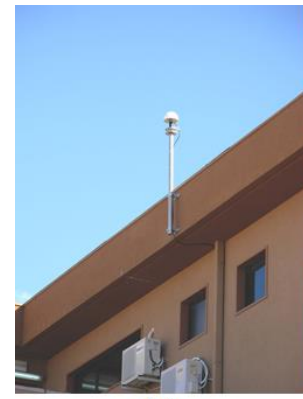

(a)

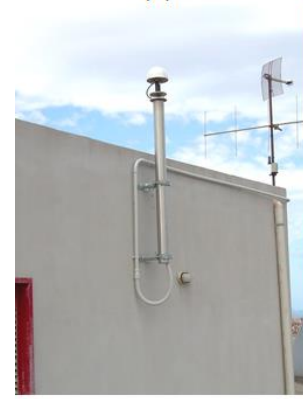

(e)

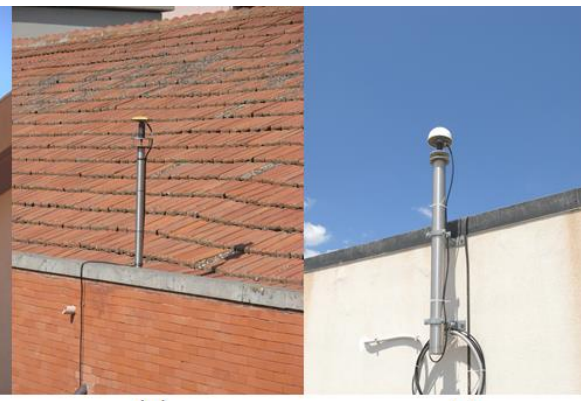

(b) (c)

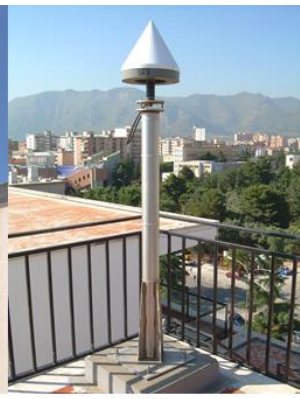

(d)

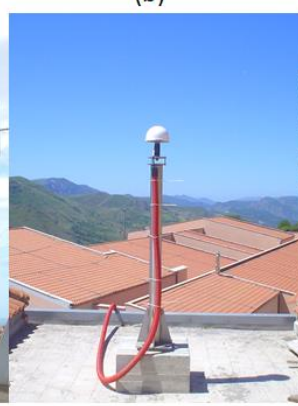

(f)

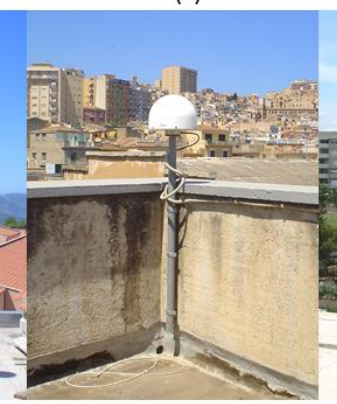

(g)

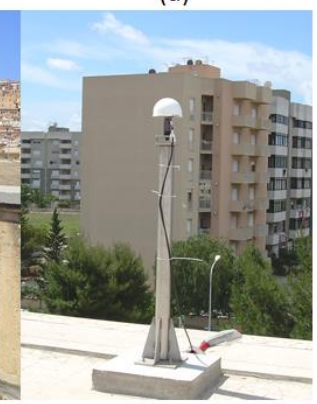

(h)

Fig. 3. Monumentation of the UNIPA CORS. From left to right and from up to bottom: (a) AGRI; (b) CALT; (c) CAMP; (d) PALE; (e) PART; (f) PRIZ; (g) TERM; (h) TRAP.

\subsection{Main characteristics of GNSS receivers and antennas}

As discussed before, the materialization of the UNIPA GNSS CORS network has been guaranteed by the collaboration with Topcon Italy that supported the scientific research with GNSS receivers and all instrumentation. This collaboration allowed the 
University to reduce costs, guaranteeing the use of the GNSS CORS data by private institutions for commercial purposes (especially for NRTK corrections). This approach is widely used in literature (Rizos, 2007), for example in the United Kingdom (UK) the Ordnance Survey Network (OSNet) permits the use of CORS data to Leica Geosystems and Trimble companies (Edwards et al., 2010; Henning, 2011).

All GNSS CORS were equipped with Topcon NET-G3 GNSS receivers, able to receive signals from both GPS and GLONASS constellations, but also Galileo frequencies. They are also equipped with an Ethernet door for their management from remote by using the Transmission Control Protocol/Internet Protocol (TCP/IP) protocol and a data storage to archive two weeks of data collected with a rate of 1 second. They were allocated within plastic lockers with more long-lasting batteries to be used when the electricity is not available.

All UNIPA CORS were also equipped with Topcon G3-A1 antennas with plateground and radome, excepting for the two CORS (PALE and TERM) already existing before the network's materialization. The first one is equipped with choke-ring antenna Topcon CR-3, the other GPS-GLONASS choke-ring antenna was already furnished by Leica (Leica AT504). All antennas and receivers were connected with RG-58 cables longer than 30 meters, installed within external pipes made of polyvinyl chloride (PVC).

\subsection{Network design, data transmission, products and available services}

All UNIPA GNSS CORS are monitored from remote and they are able to transmit data by using the Asymmetric Digital Subscriber Line (ADSL), exclusively used for the project. This technology, low-cost and easily installable, is configured with static Internet Protocol (IP) address by Telecom Italia for all available GNSS CORS, excepting for PALE CORS, directly connected to the server of the University and AGRI CORS, connected with another technology by Gruppo di Armonizzazione delle Reti della Ricerca (GARR). The routing of the network allows connecting each reference station to the main server of the Centro Universitario di Calcolo (CUC) of the University of Palermo.

In the preliminary stage of activity, from 2008 to 2012, the management was exclusively entrusted to the University of Palermo, specifically to the Geomatic Laboratory of the Department of Engineering. The software managing the network was GNSS State Monitoring And Representation Technique (Geo++® GNSMART) allowing a continuous monitoring system, recording and storing GPS data, computing and sending the differential corrections via FKP or VRS. This software is also able to record data from all GNSS CORS in Radio Technical Commission for Maritime Services (RTCM) format, checking the quality and the entirety of the data, estimating the ambiguity phase in real-time and the disturbances and the errors of the phase and code measurements.

The distribution of the data in RTCM format, used for real-time positioning, is guaranteed by Networked Transport of RTCM via Internet Protocol (NTrip), developed by EUREF to promote and spread GNSS data via internet. For post-processing positioning, GNSS data are available in RINEX format at 1, 5, 30 seconds rate. The latter are stored on the server of the University and made available to private users only after specific requests.

Since 2013, Topcon Italy has also used its software to manage the GNSS data available from UNIPA CORS. Specifically, the software Topnet was used for sending the corrections of Netgeo network in real-time (Nearest, VRS, MRS, FKP, DGPS), while the Meridiana Sat Enterprise software, implemented with "Megaserver" module, is only used for post-processing positioning systems, specifically for data recording, transferring, storing and making available online the RINEX format of the data. 


\section{MATERIALS, SOFTWARE USED AND METHODS}

\subsection{Data availability}

For this case study, the dataset refers to the period 2008 - 2012 and consists of all available data in RINEX format daily acquired (24h) from UNIPA GNSS CORS. The data availability was analysed with Network Deformation Analysis (NDA) Lite software, specifically, with the graphic interface NDA Data Quality Evaluation (DQE), developed by Galileian Plus S.r.l.

The quality check of the data with NDA Lite software was analysed over the entire time span, specifically from the Modified Julian Date (MJD) 54400 to the MJD 56400.

Other specifications were also considered for the analysis:

- The ratio between expected and collected data acquired in RINEX format;

- The ratio between the number of acquired data in dual-frequency and the amount of acquired data;

- The number of cycle slips for each session.

\subsection{Preliminary analysis}

For the preliminary analysis, two software have been used: Translation Editing Quality Check (TEQC) and QC2SKY, both open-source and available from UNAVCO website. The first one is a powerful tool for the preliminary processing of GPS, GLONASS but also Galileo observations. It also allows modifying the data format and implementing the quality check, modifying and extracting metadata. The main functions of the software are reported below and can be used separately or combined:

- Translation: conversion of the data from the original binary format to RINEX files in American Standard Code for Information Interchange (ASCII) format;

- Editing: transformation and/or extraction of metadata from RINEX files and RINEX files formatting;

- Quality Control: quality check of RINEX data.

Results from TEQC software are then processed with QC2SKY software, implemented and made freely available online by the Polytechnic of Turin (Italy). Results from these analyses are shown in bitmap format, describing the Signal-to-Noise Ratio (SNR) values and the multipath skyplots on both frequencies, the ionosphere and the first derivative of ionospheric delay. The quality check of RINEX data is based on the use of Estey and Meertens equations (Estey and Meertens, 1999).

\subsection{Geodetic framework and time-series computation}

The NDA Professional software, developed by Galileian Plus s.r.l., in collaboration with the Polytechnic of Milan and the Agenzia Spaziale Italiana (ASI), has been used to determine the geodetic framework and the time-series of all UNIPA CORS. NDA has been used in many technical-scientific applications in Italy; in particular, in 2013 for SISMA (Seismic Information System for Monitoring and Alert) project, comparing the results obtained by NDA with those of GAMIT/GLOBK to obtain a combined solution (Panza et al., 2013). In 2014 a GNSS continuous monitoring system for earth-dam deformations has been developed using NDA; the NDA results were also validated through Bernese ver 5.0 (Dardanelli et al., 2014).

The tropospheric corrections involving Saastamoinen and Niell mapping functions (Saastamoinen, 1972; Niell, 1996) and the ionospheric error determined by using the 
Klobuchar model (Klobuchar, 1996) are both implemented within the software; but also the ocean tides corrections are available, based on the Schwiderski model (Schwiderski, 1980).

NDA software adopts this correction model regardless of the receiver type. In particular, for ionosphere modelling users can select the ionosphere model available to compute and remove the ionospheric path delay. Possible choices are:

1) Zero: no ionospheric residual is added on double differenced data. It is recommended for baseline length $<5 \mathrm{Km}$;

2) Euler-Goad: the dispersive delay is estimated using the Euler-Goad algorithm;

3) Absolute: the Euler-Goad estimation average is replaced with the Klobuchar's model average;

4) Klobuchar (broadcast): the dispersive delay is computed using the Klobuchar's model and the eight model parameters are obtained from broadcast ephemerides files;

5) Klobuchar (CODE): the eight model parameters are computed by the European Centre for Orbit Determination (CODE), and distributed in RINEX navigation file data header format. If Klobuchar model with CODE parameters is selected, a valid path for CODE Global Ionospheric Map (GIM) file repository must be provided.

Additional parameters such as the Earth's rotation parameters (ERP), the ephemerides relative to the sun and the moon, the precise ephemerides (sp3 format) and the antenna phase centre position retrieved from the International GNSS Service (IGS) were also used for the analysis. Sun ephemerides are mandatory to remove the antenna satellite offset and fully exploit the sub centimetre precision of IGS precise ephemeris, while, moon ephemerides are used (together with sun ephemerides) to compute the antenna displacements.

A single baseline was used for the connection between the UNIPA and IGS CORS (Noto, Cagliari, Matera and Lampedusa). Based on the design project of the network, totally 32 baselines (with lengths between 105 and $478 \mathrm{~km}$ ) have been developed, connecting separately four UNIPA CORS to each of the IGS stations. For the baselines processing, the zenith troposphere estimation (affecting the baseline coordinates estimation) was enabled on both stations (recommended for baseline over $15 \mathrm{~km}$ ). According to the multi-frequency strategy, double-differenced observation data coming from L5 (wide-lane) and L3 (ionospheric-free) frequencies combination were used. This option is recommended within the software for baseline lengths higher than $10 \mathrm{~km}$. The Least-Squares Ambiguity De-correlation Adjustment (LAMBDA) method was used to fix the phase ambiguity (Teunissen, 2005). To estimate the final solution, the Wide-lane observation estimating the Wide-lane ambiguity and then, the ionospheric-free observations estimating the remaining Narrow-lane ambiguity were also used. Finally, the time range and the cut-off angle were set to $30 \mathrm{~s}$ and 10 degrees, respectively.

\subsection{Statistical analysis}

The statistical analysis of GNSS data has been computed by using Matlab software. In particular, the software allowed analysing the robustness of data, removing the outliers and plotting the time series over time. Then, according to the literature (Feng and Jokinen, 2017; Prikry et al., 2013; Olivares-Pulido et al., 2019) a CDF has been applied to the coordinates (X, Y, Z) of each GNSS CORS. Preliminary, an adjustment test has been also conducted on the dataset ("Lillietest"), to verify its Gaussian distribution. Then, results from GNSS analysis have been preliminary averaged applying a simple moving average (SMA) over a temporal moving window ( 1 month), during the whole period (2008 - 2012) to retrieve the long-term trend of the coordinates. 


\section{RESULTS AND DISCUSSION}

As mentioned previously, this study focuses on the analysis of the GNSS CORS network over the first period of 5 years (2008 - 2012) in which RIXEX data was collected; indeed, other experimental research by EPN, UNAVCO or IGS did not reveal the minimum time span mandatory for the GNSS CORS network analyses (Kenyeres et al., 2019). Preliminary, the coordinates and the velocities (both absolute and relative) of all GNSS CORS have been computed in the IGb08 reference frame, by using the Geo++® GNSMART and NDA Professional software. Since 2013, the collaboration with Topcon Italy for the management of the network has started and six UNIPA GNSS CORS have been included in the RDN2 network (EPN network), managed by IGMI. From this period, data was available for the national reference frame evaluation, conducted by the IGMI but also for technical research, to analyse the CORS time series, the map of horizontal and vertical velocities, weekly published on the Bollettino Bernese by the Italian GNSS Network (Italian GNSS Network 2020).

\subsection{Data availability}

The availability of the dataset was checked analysing the RINEX files during the monitored period (from MJD 54400 to MJD 56400); specifically, the RINEX files have been daily analysed over a period of 5 years, while the daily mean has been retrieved from the observation data, during the same period. Availability of single GPS satellite day by day is shown in Fig. 5 and 6; the percentage of daily satellite availability for all CORS is generally over $90 \%$. Fig. 7 and $\mathbf{8}$ show instead the number of cycle slips per single satellite day by day; the values are very low for all CORS. The total amount of expected RINEX files to be downloaded (expR), the number of files actually acquired (acqR) and their ratio (R1\%) have been reported in Table 1. In the same table, also the amount of expected observations (expO), the number of files really acquired (acqO) and their ratio (R2\%), the average value of cycle slips (Cs) for each session and another parameter called CSR have been resumed. The latter parameter is computed as follows:

$$
\text { CSR }=\frac{\text { cycle slips }}{n^{o} \text { of observation }} 1000
$$

Results confirmed the highest values of R1 for CAMP, PALE, PART, PRIZ CORS (ranging between 82 and $89 \%$ ), while values between $69 \%$ and $78 \%$ of the same parameter have been found for AGRI, CALT, TERM and TRAP CORS. The lowest value of R1 has been found for CALT CORS (69\%), because the CORS has been moved from the original site for technical reasons and a loss of data has been verified during the repositioning of the instrumentation. In general, referring to previous studies already analysing the percentage of transmitted data, the R1 values seem to be satisfactory for all GNSS CORS (Barbarella et al., 2018). Results confirmed also a strong percentage of R2 values for all GNSS CORS (R2 > 92\%), while the CSR parameter is generally less than 5 for all CORS, according to EUREF and IGS prescriptions (Boucher and Altamimi, 2011; Barbarella et al., 2018), despite the reference stations have been included in the EPN network (B classification). 


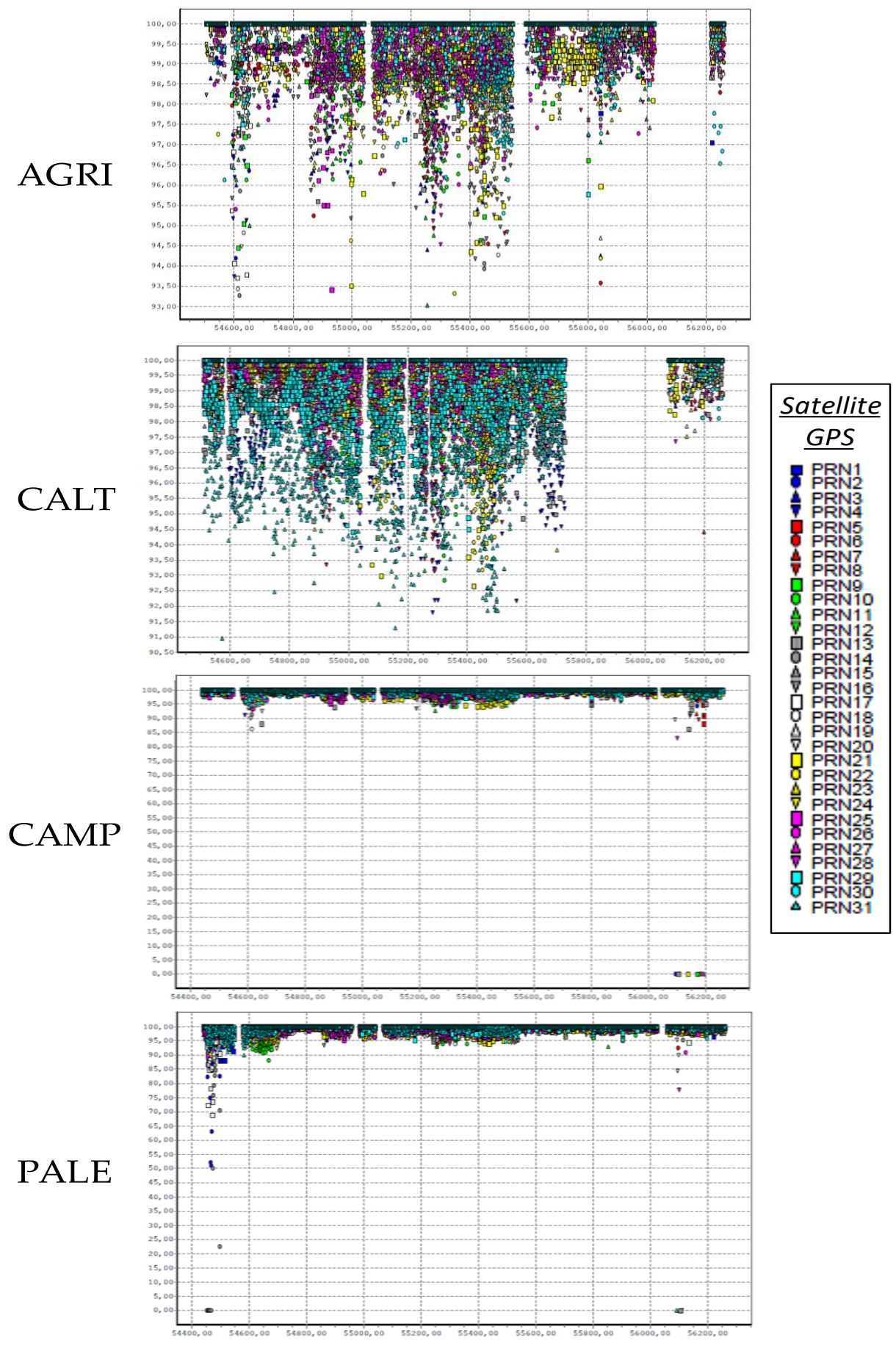

Fig. 5. Availability of single GPS satellite day by day; the x-axis represents the time (EpochsMJD), the $y$-axis represents the percentage of data availability. 

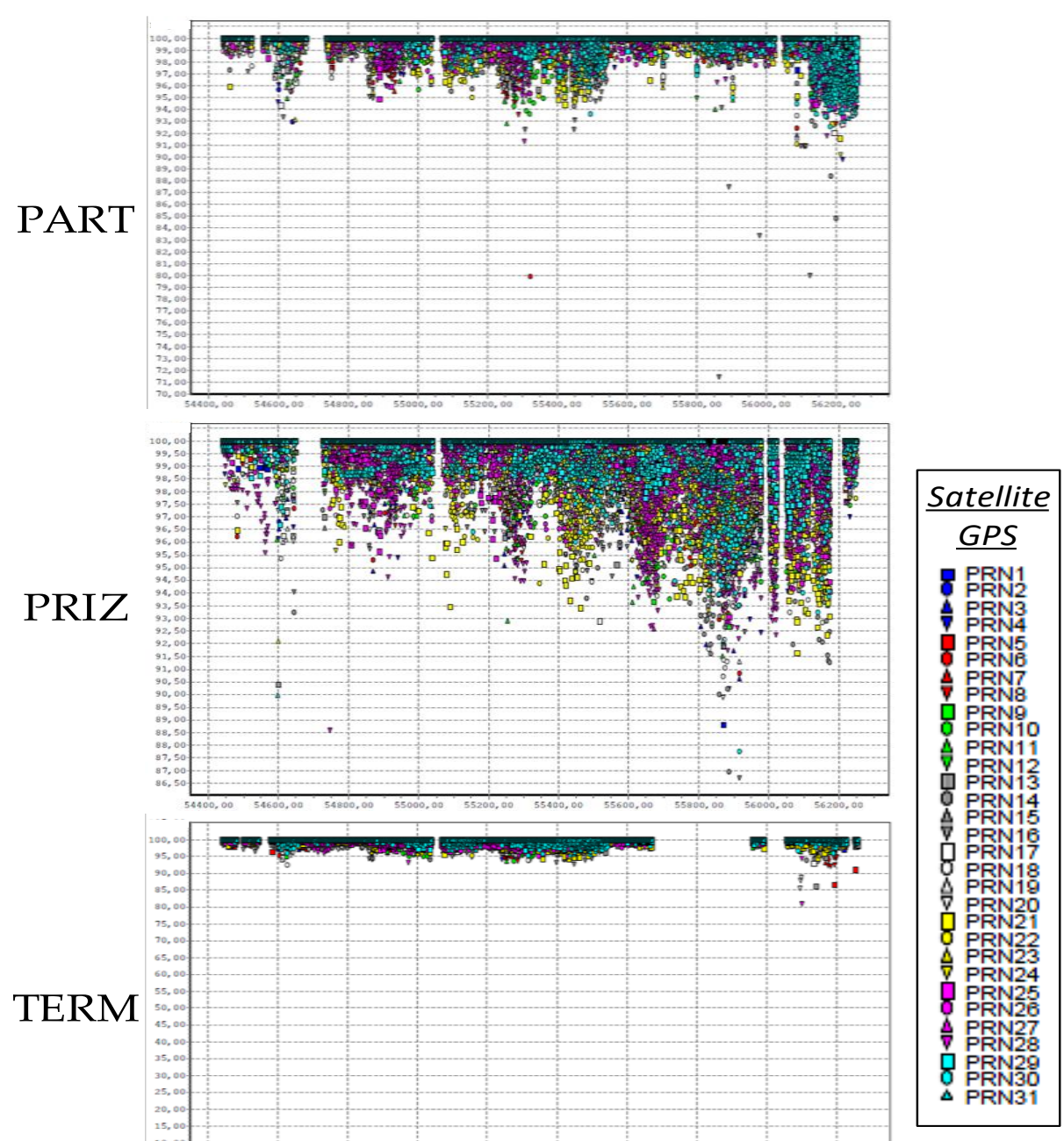

TRAP

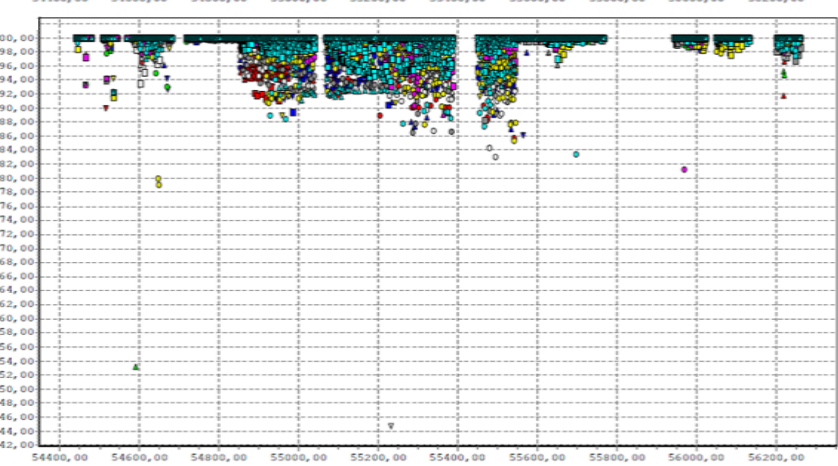

Fig. 6. Availability of single GPS satellite day by day; the x-axis represents the time (EpochsMJD), the $y$-axis represents the percentage of data availability. 
AGRI

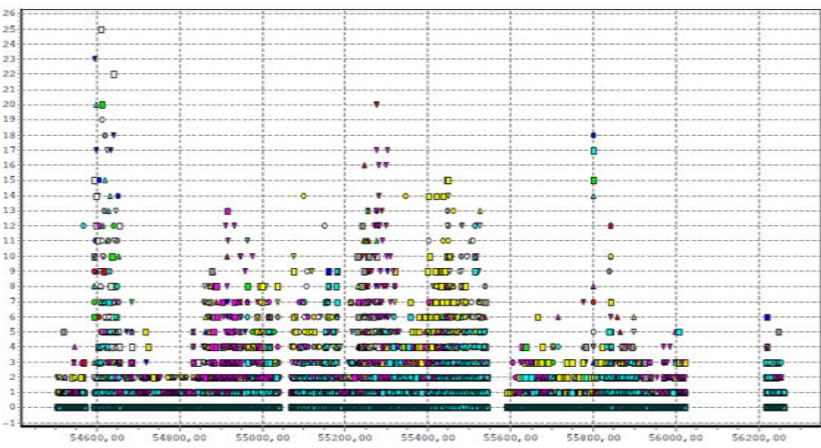

CALT

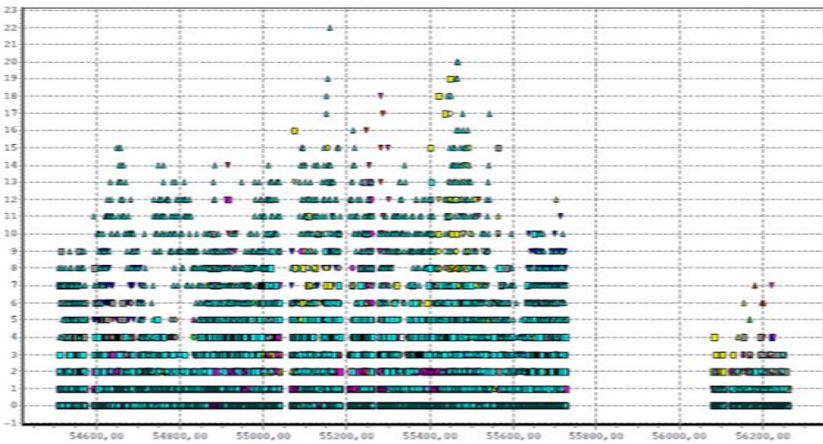

CAMP
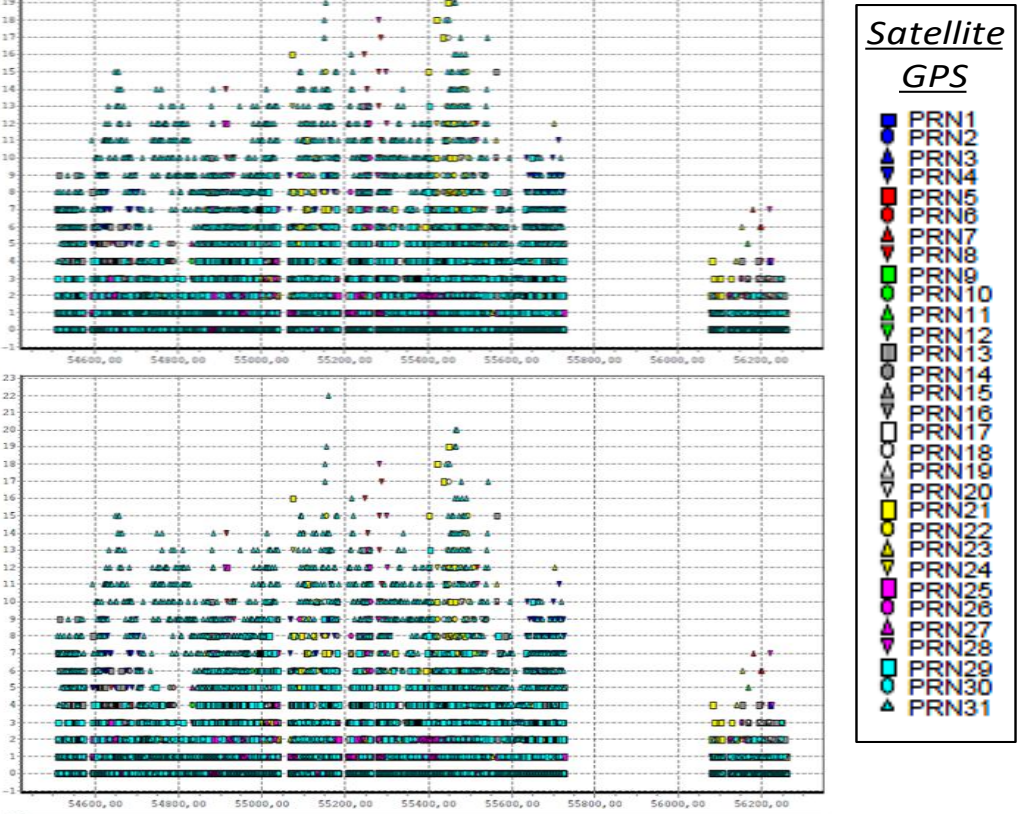

PALE

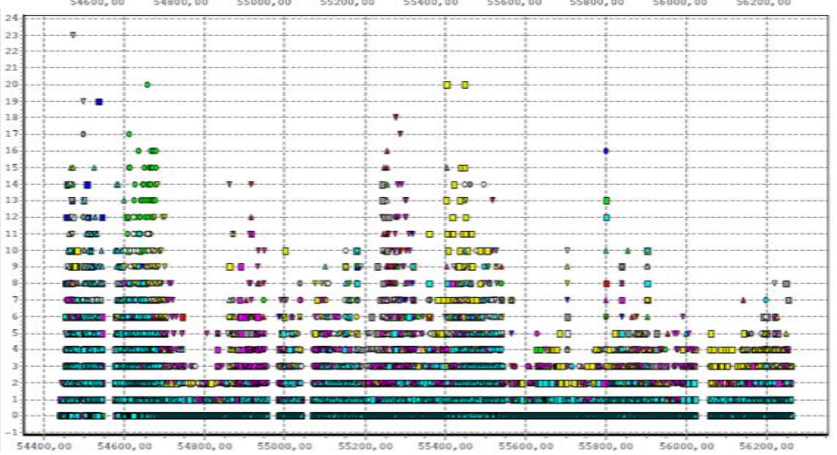

Fig. 7. Cycle slips per single satellite; the $x$-axis represents the time (Epochs-MJD), the y-axis represents the number of cycle slips. 

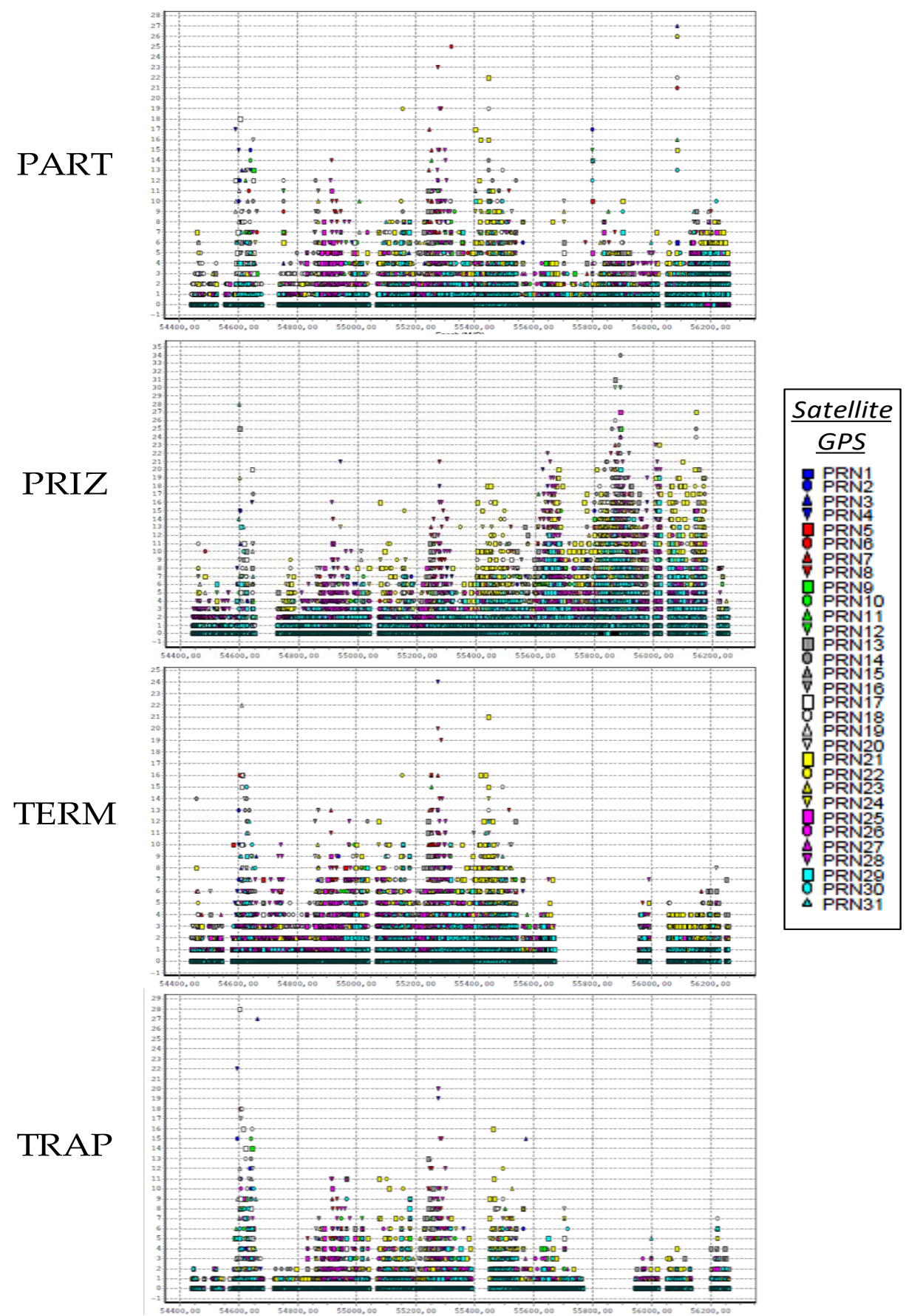

Fig. 8. Cycle slips per single satellite; the $x$-axis represents the time (Epochs-MJD), the y-axis represents the number of cycle slips. 
Table 1.

RINEX and observation data from MJD 54400 to MJD 56400

\begin{tabular}{|c|c|c|c|c|c|c|c|c|}
\hline CORS & \multicolumn{3}{|c|}{ RINEX data } & \multicolumn{5}{c|}{ Observation data } \\
\hline & exp $_{\mathbf{R}}$ & $\mathbf{a c q} \mathbf{R}$ & $\mathbf{R 1}(\boldsymbol{\%})$ & $\mathbf{e x p o}$ & $\mathbf{a c q} \mathbf{0}$ & $\mathbf{R 2}(\%)$ & $\mathbf{C s}$ & CSR \\
\hline AGRI & 1827 & 1428 & 78 & 22795 & 22458 & 99 & 6730 & 0.1 \\
\hline CALT & 1827 & 1253 & 69 & 22639 & 21042 & 93 & 2635 & 0.4 \\
\hline CAMP & 1827 & 1623 & 89 & 23355 & 22945 & 98 & 9126 & 0.1 \\
\hline PALE & 1827 & 1635 & 89 & 23321 & 22898 & 98 & 5101 & 0.2 \\
\hline PART & 1827 & 1608 & 88 & 25030 & 23908 & 96 & 14404 & 0.1 \\
\hline PRIZ & 1827 & 1507 & 82 & 25260 & 24254 & 96 & 3456 & 0.3 \\
\hline TERM & 1827 & 1300 & 71 & 23308 & 22908 & 98 & 5350 & 0.2 \\
\hline TRAP & 1827 & 1334 & 73 & 25277 & 24943 & 99 & 15660 & 0.1 \\
\hline
\end{tabular}

$\begin{array}{llllll}\text { IOD } & 0.0 & 0.25 & 0.5 & 0.75 & 1.0 \\ \text { ION } & 0.0 & 4.0 & 8.0 & 12.0 & 16.0 \\ \text { MP1 } & 0.0 & 0.5 & 1.0 & 1.5 & 2.0 \\ \text { MP2 } & 0.0 & 0.5 & 1.0 & 1.5 & 2.0 \\ \text { SN1 } & 0.0 & 2.0 & 4.0 & 6.0 & 8.0\end{array}$

Fig. 9. QC2SKY color scale. 
Table 2.

QC2SKLY skyplot (cartesian and polar).

\begin{tabular}{|c|c|c|c|c|c|c|c|}
\hline CORS & Cartesian L1 & IOD & ION & MP1 & MP2 & SNR1 & SNR2 \\
\hline AGRI & & & & & & & \\
\hline CALT & & & & & & & \\
\hline CAMP & & & & & & & \\
\hline PALE & & & & & & & \\
\hline PART & & & & & & & \\
\hline PRIZ & & & & & & & \\
\hline TERM & & & & & & & \\
\hline TRAP & & & & & & & \\
\hline
\end{tabular}

\subsection{Preliminary analyses}

The preliminary analyses have been conducted with TEQC and QC2SKY for all UNIPA GNSS CORS. Results obtained with TEQC software are plotted as functions of the elevation angle and the azimuth of the satellites at the time of observation; they refer to two different coordinate systems: polar and cartesian. In the latter, the azimuth is represented on the $\mathrm{x}$-axis and the elevation angle is on the y-axis. The $\mathrm{SNR}$ of $\mathrm{L}_{1}$ frequency is represented in colour scale in TEQC, specifically, in green the obstructions on the horizon are represented. The output from QC2SKY software shows only one colour scale for each panel, only changing the upper limit as reported in Fig. 9; the units of the ION (ionospheric delay, in meters), IOD (first derivative of ionospheric delay, in meters/minute), and MP1 
and MP2 (multipath, in meters) values are uniformly displayed. SN1 and SN2 are reported for L1 and L2 signals in $\mathrm{dBHz}$ units. The units in TEQC can not be modified, the software QC2SKY schematically shows the TEQC outputs, resampling all values in the same color scale. In particular, in Fig. 9 the skyplot of only one casual day is represented, corresponding to the date 30-06-2010, because too many representations were available from the analysis (more than 250 graphs). Fig. 9 and Table 2 show that the ionospheric delay (IOD) is always included within the range $0.00-0.25$, first derivative of ionospheric delay (ION) (Kang et al., 2019; Mitch et al., 2013) within the range $0.00-4.00$, the multipath values (for both MP1 and MP2) are included within the range $0.00-0.50$, while SNR1 and SNR2 values range between $6.00-8.00$ and $4.00-6.00$, respectively. These values are in agreement with literature (Hu et al., 2016; Baniulis et al., 2017); indeed, the Root Mean Square (RMS) MP1 of half of IGS stations is lower than $0.4 \mathrm{~m}$ and 2/3 have less than $0.5 \mathrm{~m}$; the absolute values of multipath RMS, however, do not necessarily correlate with site performance. Finally, the RMS MP2 values of half of IGS stations are lower than $0.6 \mathrm{~m}$ and less than $0.75 \mathrm{~m}$ for $2 / 3$ of IGS stations (IGS 2020).

\subsection{Geodetic reference framework analysis and CORS time-series computation}

Preliminary, the coordinates of all UNIPA GNSS CORS, referred to February 2008 have been computed in the International GNSS Service, epoch 2008.0 (IGb08) reference frame. The coordinates of the reference stations have been also computed in the European Terrestrial Reference Frame, epoch 2008.0 (ETRF2000) reference frame, by using the "Altamimi and Boucher" equations ((Boucher and Altamimi, 2011). The computation of the coordinates has been processed, analysing the available monthly dataset from GPS week 1465 to 1469 . The analysis included other IGS reference stations, such as Noto, Cagliari, Matera and Lampedusa. A prori precision of these CORS was $2 \mathrm{~mm}$ and $4 \mathrm{~mm}$, for the planimetric and altimetric components, respectively. Results obtained from the analyses are in agreement with IGS standard recommendations (IGS 2020). The weekly solutions are computed from the daily ones, evaluating for the latter the network balance with double differences. Specifically, several parameters have been evaluated for each reference station and each daily solution, such as data quality indicators, the amount of cycle slips, the amount of initial ambiguity phase, the percentage of fixed ambiguity phase and the fixing quality, the standard deviation $(\sigma)$ of the float and the final solutions. The coordinates and the standard deviations for each GNSS CORS are reported in Table 3. Also for the GNSS time-series estimation, the IGS CORS of Noto, Cagliari, Matera and Lampedusa have been considered. Fig. 10 show the geocentric components (X, Y and Z) of all GNSS CORS coordinates corresponding to the GPS epochs (MJD). Preliminary, the outliers have been removed from the time-series and the evolution of the scattered behaviour has been plotted within the range $\pm 3 \sigma$, as reported in literature (Barbarella et al., 2018; Gandolfi et al., 2016). In Table 3 also the average errors related to the X, Y, Z components of the CORS coordinates have been reported. As shown, these values are lower than $0.4 \mathrm{~mm}$, excepting for those referred to PALE CORS. Indeed, for this station, the values are included within the range $2.9-6.5 \mathrm{~mm}$, but they are even in agreement with EPN recommendations suggesting the limits up to $10-20 \mathrm{~mm}$ (Gülal et al., 2013). According to the strategy explained in section 3.3, after removing the outliers, reporting the time series within the range $\pm 3 \sigma$, the behaviour of the CORS coordinates is mainly considered linear, in agreement with (Gülal et al., 2013) (Fig. 10). 
Table 3.

UNIPA CORS geodetic positions in IGb08 and ETRF2000 systems.

\begin{tabular}{|c|c|c|c|c|c|c|}
\hline CORS & \multicolumn{3}{|c|}{ IGb08 epoch 2008.0} & \multicolumn{3}{|c|}{ ETRF2000 epoch 2008.0 } \\
\hline & $X(\mathrm{~m})$ & Y (m) & $\mathrm{Z}(\mathrm{m})$ & $(\mathrm{m})$ & $\mathrm{Y}(\mathrm{m})$ & $\mathrm{Z}(\mathrm{m})$ \\
\hline AGRI & $\begin{array}{r}49363 ? \\
0.0\end{array}$ & 0. & 0.0 & 4936331.298 & 1194330.469 & 3845900.834 \\
\hline CALT & $\begin{array}{r}4915665 \\
0.000 \\
\end{array}$ & $\begin{array}{r}12306 \\
0 .\end{array}$ & $\begin{array}{r}386134 \\
0.0 \\
\end{array}$ & 4915665.644 & 1230635.292 & 3861348.275 \\
\hline CAMP & $\begin{array}{r}4933160 \\
0.00 \\
\end{array}$ & $\begin{array}{r}11157 \\
0.0 \\
\end{array}$ & \begin{tabular}{|c|}
$3873025.139 \pm$ \\
0.0004 \\
\end{tabular} & 4933161.054 & 1115 & 38730 \\
\hline PALE & $\begin{array}{r}488953 \\
0.00 \\
\end{array}$ & $\begin{array}{r}1160 \\
0\end{array}$ & $\begin{array}{r}391473 \\
0.0 \\
\end{array}$ & 4889534.473 & 1160203.648 & 3914738.514 \\
\hline PART & $\begin{array}{r}489876 \\
0.06 \\
\end{array}$ & $\begin{array}{r}1140 \\
0 .\end{array}$ & $\begin{array}{r}39091 \\
0 . \\
\end{array}$ & 768.970 & 11408 & 3909130.415 \\
\hline PRIZ & \begin{tabular}{|c|}
$4914033.044 \pm$ \\
0.0023 \\
\end{tabular} & $\begin{array}{r}11740 \\
0.0\end{array}$ & $\begin{array}{c}3881406.106 \pm \\
0.0008\end{array}$ & 4914033.464 & 1174031.855 & 3881405.827 \\
\hline TERM & $\begin{array}{r}489036 \\
0.0\end{array}$ & $\begin{array}{r}11923 \\
0 .\end{array}$ & $\begin{array}{r}39040 \\
0.0\end{array}$ & 337 & 1192337.028 & 3.032 \\
\hline TRAF & \begin{tabular}{|c|}
$4911562.977 \pm$ \\
0.0009 \\
\end{tabular} & $\begin{array}{c}1092566.697 \pm \\
0.0003\end{array}$ & \begin{tabular}{|c|}
$3906586.062 \pm$ \\
0.0006 \\
\end{tabular} & 4911563.389 & 109256 & 3906 \\
\hline
\end{tabular}

Table 4 highlights that some of the analysed CORS exhibit more frequent gaps due to missing data and post-processing analysis failure, e.g. AGRI, TERM and TRAP CORS (Fig. 10).

Table 4.

Gaps, missing acquisitions or post-processing analysis' failure and outliers range (MJD).

\begin{tabular}{|c|c|c|}
\hline CORS & $\begin{array}{c}\text { Gaps, missing acquisitions or post- } \\
\text { processing analysis' failure }\end{array}$ & $\begin{array}{c}\text { Outliers range } \\
\text { (MJD) }\end{array}$ \\
\hline AGRI & Dec 11-Jan 12, Apr 12-Oct 12 & $\begin{array}{c}54590-54510, \\
55750-55820\end{array}$ \\
\hline CALT & Dec 09, Jun 11-May 12 & $\begin{array}{c}54650-54800, \\
55500-55650\end{array}$ \\
\hline CAMP & $\begin{array}{c}\text { Apr 08-May 08, Apr 09-May 09, Jul } \\
\text { 10-Aug 10, Apr 12-May 12 }\end{array}$ & $56050-56200$ \\
\hline PALE & May 09, Aug 09, Apr 12-May 12 & $56100-56150$ \\
\hline PART & $\begin{array}{c}\text { Mar 08, Aug 08-Sep 08, Apr 12-May } \\
\text { 12 }\end{array}$ & $55380-54000$ \\
\hline PRIZ & $\begin{array}{c}\text { Jun 08, Jul 08, Aug 08-Sep 08, Aug 09, } \\
\text { Feb 12-Oct 12 }\end{array}$ & $\begin{array}{c}54300-54800, \\
55750-55820\end{array}$ \\
\hline TERM & Mar 08-Apr 08, Jul 09, Apr 11, May 12 & $56100-56200$ \\
\hline TRAP & $\begin{array}{c}\text { Aug 08-Sep 08, Aug 09, Jul 12-Sep 10, } \\
\text { Jul 11-Jan 12, Apr 12-May 12, }\end{array}$ & $54490-54510$ \\
\hline & Aug 12-Sep 12, Dec 12 & \\
\hline
\end{tabular}


a)
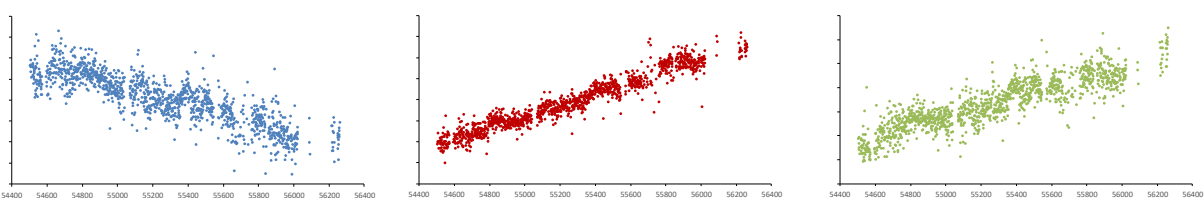

b)
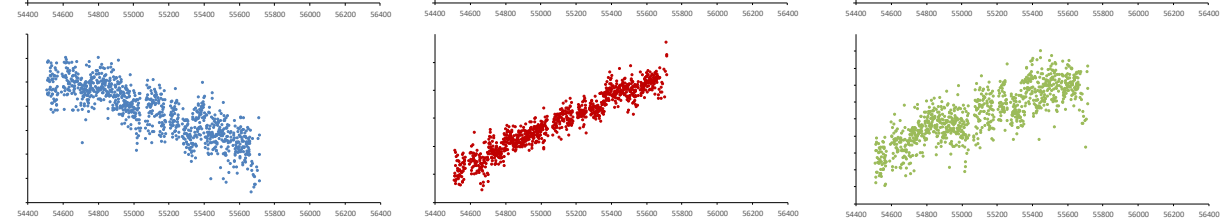

c)
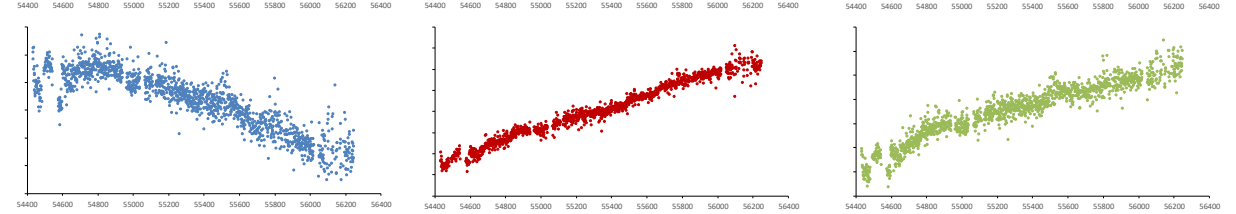

d)
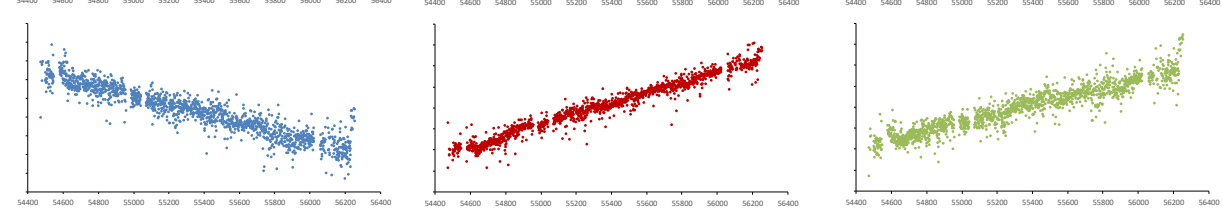

e)
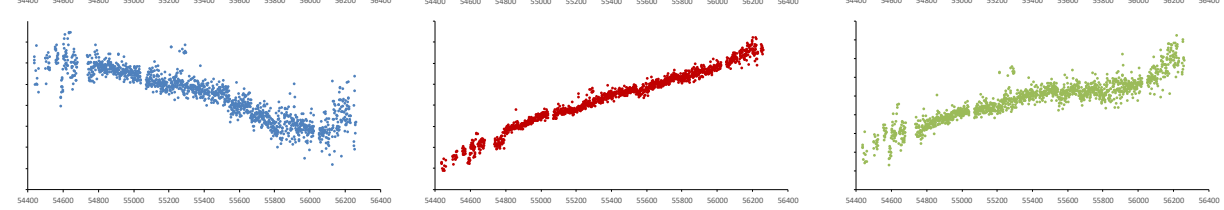

f)

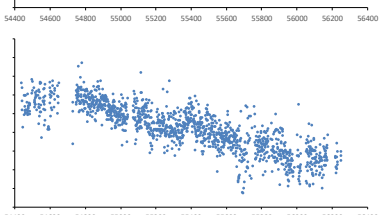

g)
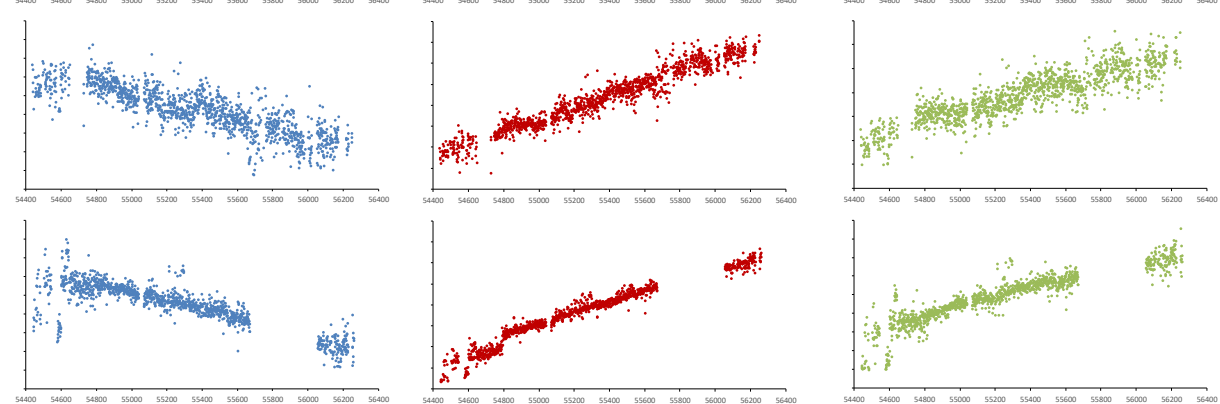

h)
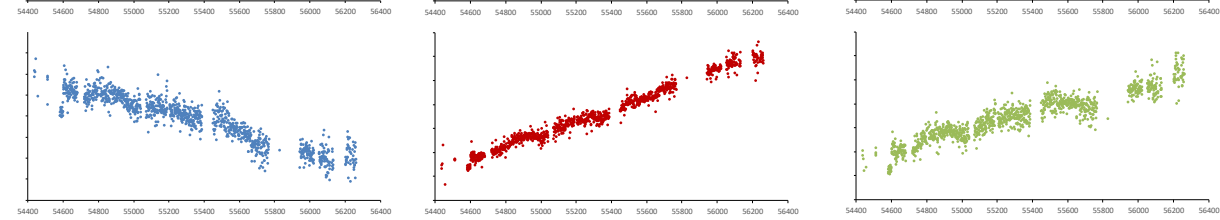

Fig. 10. Time series diagrams. a) AGRI (X, Y, Z), b) CALT (X, Y, Z), c) CAMP (X, Y, Z); d) PALE (X, Y, Z), e) PART (X, Y, Z), $f$ ) PRIZ (X, Y, Z), $g$ ) TERM (X, Y, Z), $h$ ) TRAP (X, Y, Z). In horizontals axis MJD (time), in vertical axis geodetic component ( $\mathrm{X}$ in blue, $\mathrm{Y}$ in red, $\mathrm{Z}$ in green). 
However, the time series of some UNIPA CORS is not continuously represented in this figure; indeed, several gaps, due to missing acquisitions or post-processing analysis' failure, were identified and separately shown within another table (Table 4). Best results describing the linear trend of the CORS have been found for CAMP, PALE and PART stations, where just few missing data over short periods are observed (Fig. 10). The CORS of PRIZ looks more scattered than the others. Also, some blunders not rejected by the analysis have occurred for the three components $(\mathrm{X}, \mathrm{Y}, \mathrm{Z})$; in this case, maybe the lower accuracy of the measurements can be associated to imprecise solutions derived from the post-processing analysis. Generally, the other CORS clearly show a linear trend over the long-term period. Most critical results have been obtained for CALT CORS. Specifically, for this reference station, the time series shows a long gap, from MJD 55727 to MJD 56079 (Fig. 10). In this period, indeed, data was not recorded because the CORS was not active. Only in this case, after MJD 56079 (6th January 2012), a jump occurred for the three components (X, Y, Z) after changing the materialization site of the antenna, far approximately $1.5 \mathrm{~km}$ from the previous one; also, at the beginning of the time series, data was missing because the station started acquiring data since MJD 54510, corresponding to the 14th February 2008.

\subsection{Statistical analysis (CDF)}

Fig. 11 shows the Gaussian distribution of the CDF obtained for all GNSS CORS coordinates $(\mathrm{X}, \mathrm{Y}, \mathrm{Z})$. Specifically, a deep analysis allowed the comparison and the overlapping between the theoretical Gaussian distribution and the real distribution of the CDF obtained for each CORS. Fig. 12 shows that no significant variation concerns the Z components for all CORS.

Results shown in Fig. 11 highlighted a good agreement between the theoretical Gaussian and the real CDF distributions obtained for all UNIPA CORS. Thus, another adjustment test has been improved to confirm the results, the so-called "Lilliefors" test. The latter is based on the "Kolmogorov-Smirnov" model (Massey, 1951; Lilliefors, 1967) and it is implemented by using the Matlab software.

This test is able to verify if data is retrieved from a Gaussian distribution (initial hypothesis, $\mathrm{h}=0$ ), without any other specifications about the mean value and the variance of the distribution.

Specifically, the test has been implemented for each variable and each CORS, considering three different significance levels $(\alpha=1 \%, 5 \%, 10 \%)$ and the solution is able to reveal if the hypothesis is confirmed $(\mathrm{h}=0)$ or rejected $(\mathrm{h}=1)$. In the first case, the Gaussian distribution of the dataset will be confirmed, otherwise, the distribution of the dataset will not follow the Gaussian distribution.

Results confirmed the rejection of the initial hypothesis $(\mathrm{h}=1)$ for all CORS coordinates $(\mathrm{X}, \mathrm{Y}, \mathrm{Z})$. This is probably due to the analysis of a long time series evolution, indeed, little shifts between the theoretical and the real CDF distributions allow rejecting the initial hypothesis. 
a)

b)

c)

d)

e)

f)

g)

h)
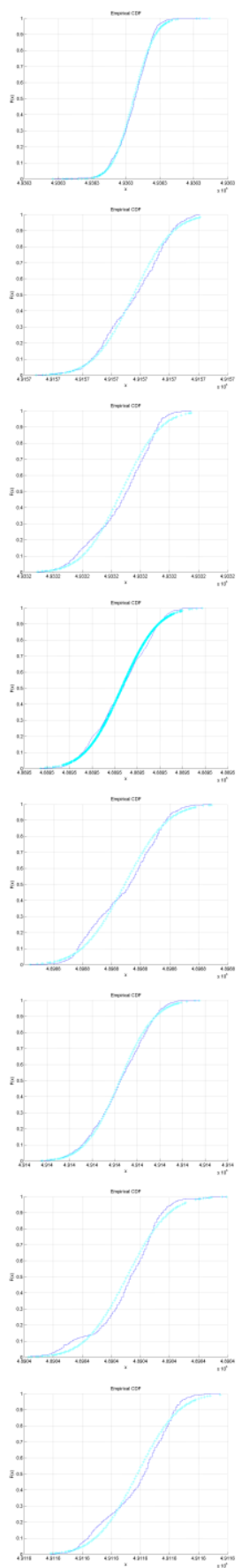
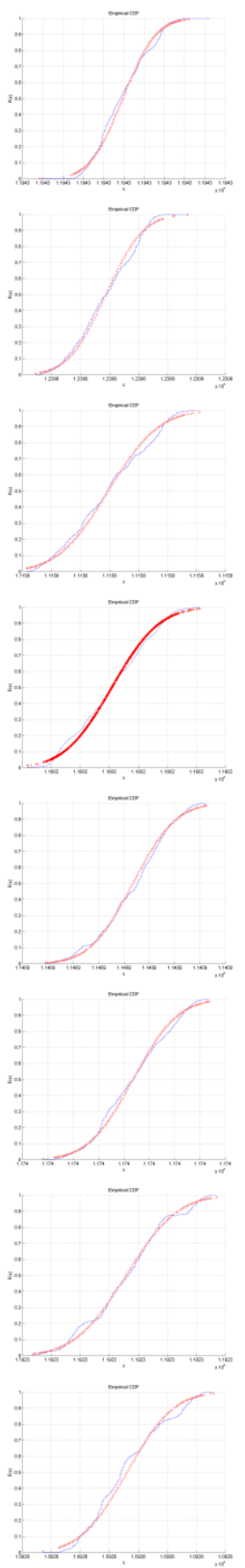
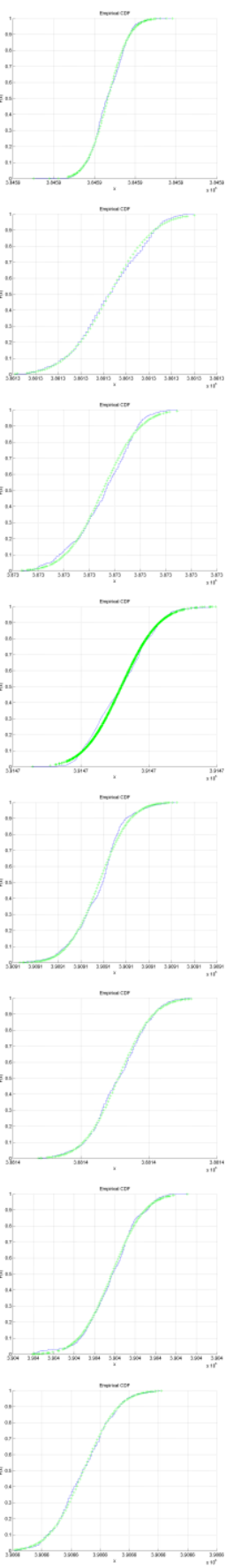

Fig. 11. CDF diagrams; in $\mathrm{x}$-axis the coordinates values (X, $\mathrm{Y}$, and $\mathrm{Z}$ ), in $\mathrm{y}$-axis the percentage of probability density functions. In blue the real CDF, in cyan, red and green the empirical CDF for $\mathrm{X}, \mathrm{Y}$ and $\mathrm{Z}$ respectively. $a$ ) AGRI, $b$ ) CALT, $c$ ) CAMP; $d$ ) PALE, $e$ ) PART, $f$ ) PRIZ, $g$ ) TERM, $h$ ) TRAP. 
a)

b)

c)

d)

e)

f)

g)

h)
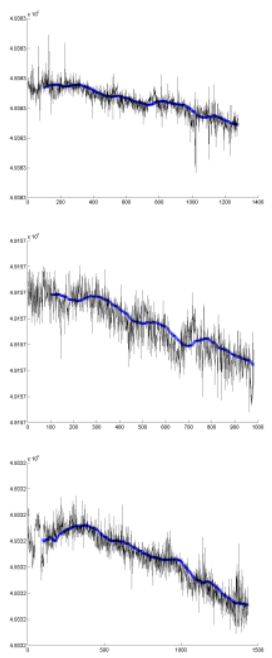

)
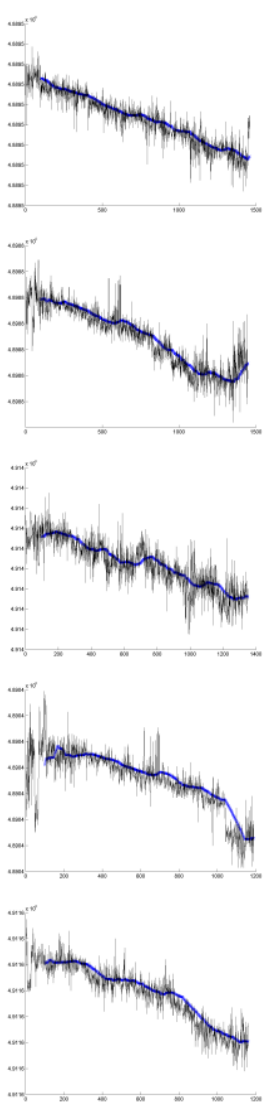
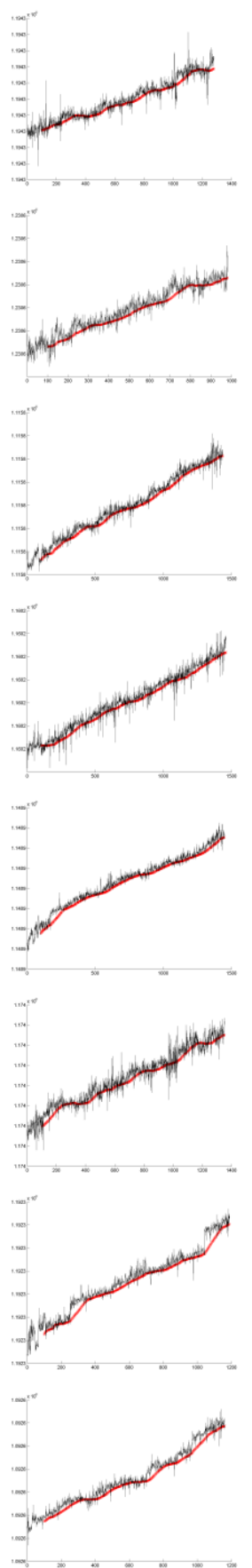
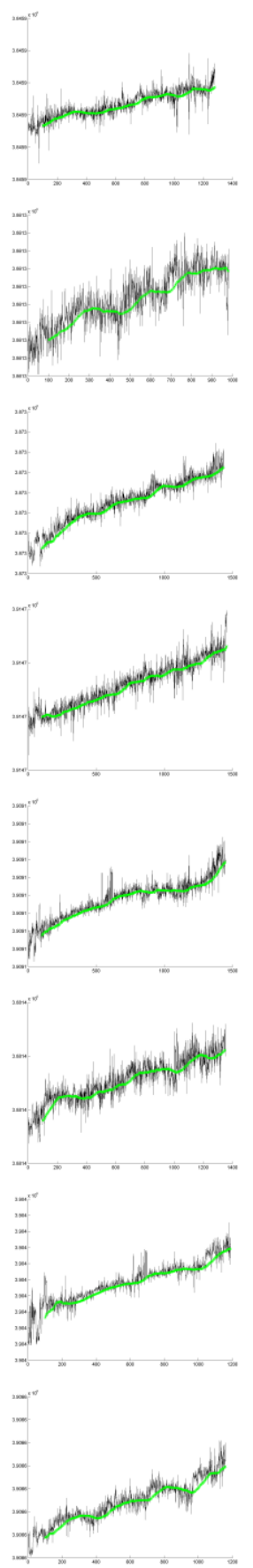

Fig. 12. Diagrams of the single moving average of time series; black line the time series data $(\mathrm{X}, \mathrm{Y}, \mathrm{Z}$ ), coloured line the moving average (X in blue, $\mathrm{Y}$ in red, $\mathrm{Z}$ in green). $a$ ) AGRI, $b$ ) CALT, $c$ ) CAMP; $d$ ) PALE, $e$ ) PART, $f$ ) PRIZ, $g$ ) TERM, $h$ ) TRAP. 
Considering also the scattered behaviour of all CORS coordinates reported in the same figure (Fig. 12), a moving average has been overimposed on the GNSS time-series to determine the long-term trend of the coordinates, without considering the variations over short periods.

Finally, a t-Student test has been implemented on the average values of the coordinates to analyse the significance of the GNSS coordinates' variations. The comparison has been made with the mean of the previous year, with $\alpha=0.05$, considering as initial hypothesis $(h=0)$ that the variations between the average values were not statistically relevant. Results confirmed the rejection of the initial hypothesis $(h=1)$, indeed the average values significantly change for all GNSS CORS, year by year. More generally, the statistical analysis of the GNSS time-series during the period 2008 - 2012 highlighted substantial statistical changes of the CORS positions.

\section{CONCLUSIONS}

This study describes the main steps for the development of a new infrastructure, to realize a GNSS CORS network in the central-western part of Sicily (Italy), during the period 2008-2012.

The analysis of the data availability highlighted a relevant percentage of acquired data, compared to those expected, for CAMP, PALE, PART, PRIZ CORS; lower values have been found for AGRI, CALT, TERM and TRAP CORS, but generally satisfactory. All UNIPA CORS, instead, have shown a substantial amount of acquired data (also in double frequency). The CSR parameter, for each CORS, is also in agreement with the recommendations available for the reference stations involved for the determination of the EUREF reference system. The preliminary analyses of the dataset demonstrated that the ionospheric delay, the first derivative of ionospheric delay, the multipath and SNR values are included within a range already confirmed by other similar experimental research. The residual values of the coordinates for the geodetic reference framework are generally submillimetric, excepting for two CORS with millimetric residuals. The precisions of the CORS coordinates are in agreement with those required by the RDN2 national network managed by the IGMI. The trend of the time series is almost linear for all GNSS CORS over the analysed period. Only for one CORS the analysis highlighted a gap within the time series, due to the change of the installation site. The statistical tests based on the CDF and the moving average analyses highlighted a good agreement of the coordinates with the Gaussian distribution over time.

These analyses validated the use of CORS within wider networks (e.g. RDN2) already used for the materialization of the geodetic framework (Maseroli, 2015) and for the new realization of more recent European reference systems (ITRF2014, Kenyeres et al., 2019).

Currently, other researches are being developing to analyse the GNSS time series of UNIPA CORS network over a wider period (10 years at least) by using innovative techniques, such as the use of Precise Point Positioning (PPP) with freely available software $($ RTKlib). From these results, more details about the horizontal and vertical velocity fields will be investigated to analyse the geodynamic evolution of a highly seismic land (Sicily).

\section{ACKNOWLEDGMENT}

The software used in this work is Network Deformation Analysis (NDA) Professional; developed by Galileian Plus s.r.l., Politecnico Milano and Agenzia Spaziale Italiana (ASI). 
The authors are grateful to the developer also for his technical support. The authors would like to thank the anonymous reviewers for their constructive comments and useful suggestions.

\section{R E F E R E N C E S}

Abidin, H.Z., Haroen, T.S., Adiyanto, F.H., Andreas, H., Gumilar, I., Mudita, I., Soemarto, I. (2015) On the establishment and implementation of GPS CORS for cadastral surveying and mapping in Indonesia. Survey Review, 47 (340), 61-70.

Altiner, Y., Söhne, W., Güney, C., Perlt, J., Wang, R., Muzli, M. (2013) A geodetic study of the 23 October 2011 Van, Turkey earthquake. Tectonophysics, 588, 118-134.

Anderson, R., Chin, M., Cline M., Hoar, D., Murray O., Stone W. (2000) NATIONAL CONTINUOUSLY OPERATING REFERENCE STATION (NATIONAL CORS) SITE MONUMENTATION FINAL REPORT December 20, 2000 Available online: URL https://kb.unavco.org/kb/assets/285/CORS_Monumentation.pdf [Accessed Feb 2020].

Angrisano, A., Gaglione, S., Gioia, C. (2013) Performance assessment of aided global navigation satellite system for land navigation. IET Radar, Sonar and Navigation, 7 (6), 671-680.

Avallone, A., Selvaggi, G., D'Anastasio, E., D'Agostino, N., Pietrantonio, G., Riguzzi, F., Serpelloni, E., Anzidei, M., Casula, G., Cecere, G., D'Ambrosio, C., De Martino, P., Devoti, R., Falco, L., Mattia, M., Rossi, M., Obrizzo, F., Tammaro, U., and Zarrilli, L. (2010) The RING network: Improvements to a GPS velocity field in the central Mediterranean. Annals of Geophysics, 53 (2), 39-54.

Baniulis, R.; Galinauskas, K.; Marozas, L.; Parseliunas, E.; Petniunas, M.; Puskorius, V. (2017) An Analysis of the Performance and Coordinates Time Series of CORS Network LitPOS (2017). Proceedings - 2017 Baltic Geodetic Congress (BGC) Geomatics, art. no. 8071443, 45-48.

Barbarella, M., Gandolfi S., Tavasci L. (2018) Monitoring of the italian GNSS geodetic reference frame. Lecture Notes in Geoinformation and Cartography, 59-71.

Baroni, L., Cauli, F., Farolfi, G., Maseroli, R. (2009) Final results of the Italian «Rete Dinamica Nazionale» (RDN) of Istituto Geografico Militare Italiano (IGMI) and its alignment to ETRF2000. Bollettino di Geodesia e Scienze Affini, 68 (3), 287-317.

Barreca G., Bruno V., Dardanelli G., Guglielmino F., Lo Brutto M., Mattia M., Pipitone C., Rossi M. (2020) An integrated geodetic and InSAR technique for the monitoring and detection of active faulting in southwestern Sicily. Annals of Geophysics, 63, art. no. EP03.

Benciolini, B., Biagi, L., Crespi, M., Manzino, A., Roggero, M. (2006) Linee guida per la realizzazione di reti di stazioni permanenti di servizio. Bollettino di Geodesia e Scienze Affini, 65 (2), 90-121.

Boucher, C., Altamimi Z. (2011) Memo: Specifications for reference frame fixing in the analysis of EUREF GPS campaign; 18-05-2011, Version 8. 2011. Available online: URL http://etrs89.ensg.ign.fr/memo-V8.pdf [Accessed Feb 2020].

Bruyninx C. (2019) GUIDELINES FOR EPN STATIONS \& OPERATIONAL CENTRES EPN. Available on line :URL:http://epncb.oma.be/_documentation/guidelines/guidelines_station operationalcentre.pdf. [Accessed Feb 2020].

Bruyninx, C., Habrich, H., Söhne, W., Kenyeres, A., Stangl, G., Völksen, C. (2012) Enhancement of the EUREF permanent network services and products. International Association of Geodesy Symposia, 136, 27-34.

Dabove, P., Di Pietra, V. (2019) Single-Baseline RTK Positioning Using Dual-Frequency GNSS Receivers Inside Smartphones. Sensors, 19, 430

Dardanelli, G., Carella, M., Integrated surveying with mobile mapping system, EGNOS, NRTK and laser technologies in the park "Ninni Cassarà" in Palermo. (2013) ISPRS Annals of the Photogrammetry, Remote Sensing and Spatial Information Sciences, 2 (2W1), 95-100. 
Dardanelli, G., Pipitone, C. (2017) Hydraulic models and finite elements for monitoring of an earth dam, by using GNSS techniques. Periodica Polytechnica Civil Engineering, 61 (3), 421-433.

Dardanelli, G., Paliaga, S., Allegra, M., Carella, M., Giammarresi, V. (2015) Geomatic applications tourban park in Palermo. Geographia Technica, 10 (1), pp. 28-43.

Dardanelli, G., La Loggia, G., Perfetti, N., Capodici, F., Puccio, L., Maltese, A. (2014) Monitoring displacements of an earthen dam using GNSS and remote sensing. Proceedings of SPIE - The International Society for Optical Engineering, 9239, art. no. 923928.

Ebolese, D., Lo Brutto, M., Dardanelli, G. (2019) Uav survey for the archaeological map of lilybaeum (Marsala, Italy). In the ISPRS Annals of the Photogrammetry, Remote Sensing and Spatial Information Sciences, 42 (2/W11), 495-502.

Edwards, S.J., Clarke, P.J., Penna, N.T., Goebell, S. (2010) An examination of network RTK GPS services in great Britain. Survey Review, 42 (316), 107-121.

Erenoglu, R.C. (2017) A comprehensive evaluation of GNSS- and CORS-based positioning and terrestrial surveying for cadastral surveys. Survey Review, 49 (352), 28-38.

Estey, L.H., Meertens, C.M. (1999) TEQC: The Multi-Purpose Toolkit for GPS/GLONASS Data. GPS Solutions, 3 (1), 42-49.

Fazio, L., Lo Brutto, M., Dardanelli, G. (2019) Survey and virtual reconstruction of ancient roman floors in an archaeological context. In the ISPRS Annals of the Photogrammetry, Remote Sensing and Spatial Information Sciences, 42 (2/W11), 511-518.

Feng, S., Jokinen, A. (2017) Integer ambiguity validation in high accuracy GNSS positioning. GPS Solutions, 21 (1), 79-87.

Forlani, G., Dall'Asta, E., Diotri, F., di Cella, U.M., Roncella, R., Santise, M. (2018) Quality assessment of DSMs produced from UAV flights georeferenced with on-board RTK positioning. Remote Sensing, 10 (2), art. no. 311.

Fotopoulos, G., Cannon, M.E. (2001) An Overview of Multi-Reference Station Methods for cmLevel Positioning. GPS Solutions, 4 (3).

Gandolfi, S.; Tavasci, L.; Poluzzi, L. (2016) Improved PPP performance in regional networks. GPS Solutions, 20 (3), 485-497.

GeoDAF. Available online: URL http://geodaf.mt.asi.it/gps_page.html [Accessed Feb 2020].

Gordini, C., Abbondanza, C., Barbarella, M. (2007) GNSS network real time positioning: Testing procedure to evaluate the accuracy of a geodetic moving antenna. In International Archives of the Photogrammetry, Remote Sensing and Spatial Information Sciences - ISPRS Archives, 36 (5C55).

Grejner-Brzezinska, D.A., Kashani, I., Wielgosz, P. (2005) On accuracy and reliability of instantaneous network RTK as a function of network geometry, station separation, and data processing strategy. GPS Solutions, 9 (3), 212-225.

Grejner-Brzezinska, D.A., Kashani, I., Wielgosz, P., Smith, D.A., Spencer, P.S.J., Robertson, D.S., Mader, G.L. (2005) The impact of the external ionospheric models on the accuracy of RTK position estimation. Proceedings of the Institute of Navigation, National Technical Meeting 2005, 462-470.

Gülal, E.; Erdoğan, H.; Tiryakioğlu, I. (2013) Research on the stability analysis of GNSS reference stations network by time series analysis. Digital Signal Processing, (6), 1945-1957.

Henning, W. (2011) Best methods for high accuracy real time GNSS positioning from a single reference station. CORS and OPUS for engineers: Tools for surveying and mapping applications, 173-180.

Hu, Y.; Cheng, L.; Wang, X. (2016) Quality analysis of the campaign GPS stations observation in Northeast and North China. Geodesy and Geodynamics, 7 (2), 87-94.

Huang, Z., Huang, D., Xu, Z., Xu, Z. (2011) GPS vehicle positioning monitoring system integrated with CORS and Mobile GIS. In Procedia Environmental Sciences, 10 (PART C), 2498-2504.

HxGN SmartNet. Available online: URL https://hxgnsmartnet.com/it-it/ [Accessed Feb 2020]. 
Italian GNSS Network. Available online: URL http://retegnssveneto.cisas.unipd.it/gpsitn/ [Accessed Feb 2020].

IGS. Available online: URL https://kb.igs.org/hc/en-us/articles/204229743-Questions-about-the-dataquality-graphs [Accessed Feb 2020].

Jing-xiang, G., Hong, H. (2009) Advanced GNSS technology of mining deformation monitoring. Procedia Earth and Planetary Science, 1 (1), 1081-1088.

Lilliefors, H.W. (1967) On the Kolmogorov-Smirnov Test for Normality with Mean and Variance Unknown. Journal of the American Statistical Association, 62 (318), 399-402.

Marais, J., Beugin, J., Berbineau, M. (2017) A Survey of GNSS-Based Research and Developments for the European Railway Signaling. IEEE Transactions on Intelligent Transportation Systems, 18 (10), art. no. 7857080, 2602-2618.

Massey, F.J. (1951) The Kolmogorov-Smirnov Test for Goodness of Fit. Journal of the American Statistical Association, 46 (253), 68-78.

Maseroli, R. (2015) Evoluzione del Sistema Geodetico di Riferimento in Italia: la RDN2. Bollettino della Associazione Italiana di Cartografia, (153), 19-44.

Mitch, R.H., Psiaki, M.L., Tong, D.M. (2013) Local ionosphere model estimation from dualfrequency global navigation satellite system observables. Radio Science, 48 (6), 671-684.

Niell, A.E. (1996) Global mapping functions for the atmosphere delay at radio wavelengths. Journal of Geophysical Research, 101, 3227-3246.

NetGeo. Available online: URL http://www.netgeo.it/page.php?Id=62 [Accessed Feb 2020]. Italian GNSS Network. Available online: URL http://retegnssveneto.cisas.unipd.it/gpsitn/ [Accessed Feb 2020].

Kang, S., Song, J., Han, D., Kim, B., So, H., Kim, K.-J., Kee, C. (2019) A new method to improve the detection of co-seismic ionospheric disturbances using sequential measurement combination. Sensors, 19 (13), art. no. 2948.

Klobuchar, J.A. (1996) Ionospheric Effects on GPS. In Global Positioning System: Theory and Applications, American Institute of Aeronautics and Astronautics: Reston, VA, USA; Chapter 12; Volume 1, 485-515.

Kenyeres, A., Bellet, J.G., Bruyninx, C.,Caporali, A., de Doncker F., Droscak, B., Duret, A., Franke, P., Georgiev, I., Bingley, R., Huisman, L., Jivall, L., Khoda, O., Kollo, K., Kurt, A.I., Lahtinen, S., Legrand, J., Magyar, B., Mesmaker, D., Morozova, K., Nágl, J., Özdemir, S., Papanikolaou, X., Parseliunas, E., Stangl, G., Ryczywolski, M., Tangen, O.B., Valdes, M., Zurutuza, J., Weber, M. (2019) Regional integration of long-term national dense GNSS network solutions. GPS Solutions, 23 (4), art. no. 122.

Kenyeres, A., Bruyninx, C. (2004) EPN coordinate time series monitoring for reference frame maintenance. GPS Solutions, 8 (4), 200-209.

Kim, J., Song, J., No, H., Han, D., Kim, D., Park, B., Kee, C. (2017) Accuracy improvement of DGPS for low-cost single-frequency receiver using modified Flächen Korrektur parameter correction. ISPRS Int. J. of Geo-Information, 6 (7), art. no. 222.

Kenyeres, A., Figurski, M., Kamiński, P., Legrand, J., Bruyninx, C., Habrich, H. (2009) Homogeneous reprocessing of the EUREF permanent network: First experiences and comparisons. Bollettino di Geodesia e Scienze Affini, 68 (3), 207-218.

Olivares-Pulido, G., Terkildsen, M., Arsov, K., Teunissen, P.J.G., Khodabandeh, A., Janssen, V.A (2019) 4D tomographic ionospheric model to support PPP-RTK. Journal of Geodesy, 93 (9), 1673-1683.

Osório, I., Cunha, M. (2013) The Role of the TRS in Precision Agriculture: DGPS with EGNOS and RTK Positioning Using Data from NTRIP Streams. In International Association of Geodesy Symposia, 138, 277-282.

Panza, G.F., Peresan, A., Magrin, A., Vaccari, F., Sabadini, R.; Crippa, B.; Marotta, A.M., Splendore, R., Barzaghi, R.; Borghi, A., Cannizzaro, L., Amodio, A.; Zoffoli, S. (2013) The SISMA 
prototype system: Integrating Geophysical Modeling and Earth Observation for time-dependent seismic hazard assessment. Natural Hazards, 69 (2), 1179-1198.

Prikry, P., Sreeja, V., Aquino, M., Jayachandran, P.T. (2013) Probabilistic forecasting of ionospheric scintillation and GNSS receiver signal tracking performance at high latitudes. Annals of Geophysics, 56 (2).

Pipitone, C., Maltese, A., Dardanelli, G., Brutto, M.L., Loggia, G.L. (2018) Monitoring water surface and level of a reservoir using different remote sensing approaches and comparison with dam displacements evaluated via GNSS. Remote Sensing, 10 (1), art. no. 71.

Radicioni, F., Stoppini A (2019) Umbria's new multi-constellation GNSS network. Geomedia (23), 4, 6-11.

Rizos, C. (2007) Alternatives to current GPS-RTK services and some implications for CORS infrastructure and operations. GPS Solutions, 11 (3), 151-158.

Rizos, C., Satirapod, C. (2011) Contribution of GNSS CORS infrastructure to the mission of modern geodesy and status of GNSS CORS in Thailand. Engineering Journal, 15 (1), 25-42.

Robustelli, U., Baiocchi, V., Pugliano, G. (2019) Assessment of Dual Frequency GNSS Observations from a Xiaomi Mi 8 Android Smartphone and Positioning Performance Analysis. Electronics, 8, 91.

Saastamoinen, J. (1972) Atmospheric correction for troposphere and stratosphere in radio ranging of satellites. In The Use of Artificial Satellites for Geodesy; Henriksen, S.W., Mancini, A., Chovitz, B.H., Eds.; AGU: Washington, WA, USA, 1972; Volume 15, 247-252.

Stocchi, P., Antonioli, F., Montagna, P., Pepe, F., Lo Presti, V., Caruso, A., Corradino, M., Dardanelli, G., Renda, P., Frank, N., Douville, E., Thil, F., de Boer, B., Ruggieri, R., Sciortino, R., Pierre, C. (2017) A stalactite record of four relative sea-level highstands during the Middle Pleistocene Transition. Quaternary Science Reviews, 173, 92-100.

Soler, T. (2011) CORS and OPUS for engineers: Tools for surveying and mapping applications, 1st ed.; American Society of Civil Engineers (ASCE), Reston (USA), 1-186.

Snay, R.A., Soler, T. (2008) Continuously operating reference station (CORS): History, applications, and future enhancements. Journal of Surveying Engineering, 134 (4), 95-104.

Schwiderski, E.W. (1980) On charting global ocean tides. Reviews of Geophysics, 18, 243-268.

Teunissen, P.J.G. (2005) Integer aperture bootstrapping: A new GNSS ambiguity estimator with controllable fail-rate. Journal of Geodesy, 79 (6-7), 389-397.

Vespe, F., Bianco, G., Fermi, M., Ferraro, C., Nardi, A., Sciarretta, C. (2000) The Italian GPS Fiducial Network: Services and products. Journal of Geodynamics, 30 (3), 327-336.

Wanninger, L. (2003) Virtual reference stations (VRS). GPS Solutions, 7 (2), 143-144.

Zhang, J., Lachapelle, G. (2001) Precise estimation of residual tropospheric delays using a regional GPS network for real-time kinematic applications. Journal of Geodesy, 75 (5-6), 255-266.

Zhang, Z., Zhan, X. (2016) GNSS spoofing network monitoring based on differential pseudorange. Sensors (Switzerland), 16 (10), art. no. 1771. 